\title{
Towards the development of a technology for art therapy and dementia: Definition of needs and design constraints
}

\author{
Alex Mihailidis, Scott Blunsden, Jennifer Boger, Brandi Richards, \\ Krists Zutis, Laurel Young, and Jesse Hoey
}

Version Post-Print/Accepted Manuscript

Citation Mihailidis, A., Blunsden, S., Boger, J., Richards, B., Zutis, K., Young, L. (published version) and Hoey, J. (2010). Towards the Development of a Technology for Art Therapy and Dementia: Definition of Needs and Design Constraints. Arts in Psychotherapy, 37(4), 293-300.

Copyright / License

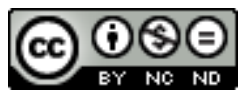

This work is licensed under a Creative Commons AttributionNonCommercial-NoDerivatives 4.0 International License.

Publisher's Statement The final publication is available via Elsevier at https://dx.doi.org/10.1016/j.aip.2010.05.004.

Always cite the published version, so the author(s) will receive recognition through services that track citation counts, e.g. Scopus. If you need to cite the page number of the TSpace version (original manuscript or accepted manuscript) because you cannot access the published version, then cite the TSpace version in addition to the published version using the permanent URI (handle) found on the record page. 


\section{Accepted Manuscript}

Title: Towards the Development of a Technology for Art Therapy and Dementia: Definition of Needs and Design Constraints

Authors: Alex Mihailidis, Scott Blunsden, Jennifer Boger, Brandi Richards, Krists Zutis, Laurel Young, Jesse Hoey

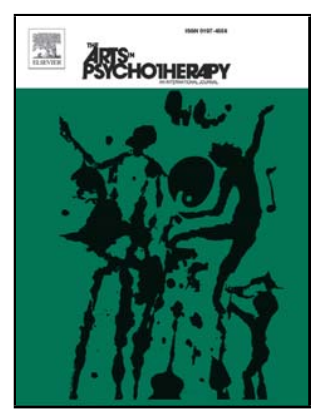

PII:

DOI:

Reference:

S0197-4556(10)00066-3

To appear in: $\quad$ The Arts in Psychotherapy

Received date: $\quad 12-3-2010$

Revised date: $\quad 14-5-2010$

Accepted date: $\quad 16-5-2010$

Please cite this article as: Mihailidis, A., Blunsden, S., Boger, J., Richards, B., Zutis, K., Young, L., \& Hoey, J., Towards the Development of a Technology for Art Therapy and Dementia: Definition of Needs and Design Constraints, The Arts in Psychotherapy (2008), doi:10.1016/j.aip.2010.05.004

This is a PDF file of an unedited manuscript that has been accepted for publication. As a service to our customers we are providing this early version of the manuscript. The manuscript will undergo copyediting, typesetting, and review of the resulting proof before it is published in its final form. Please note that during the production process errors may be discovered which could affect the content, and all legal disclaimers that apply to the journal pertain. 
Running Head: DESIGN NEEDS FOR TECHNOLOGY AND ART THERAPY

\section{Towards the Development of a Technology for Art Therapy and Dementia:}

\section{Definition of Needs and Design Constraints}

Alex Mihailidis ${ }^{a, b}$, Scott Blunsden ${ }^{c}$, Jennifer Boger ${ }^{a, b}$, Brandi Richards $^{c}$, Krists Zutis ${ }^{c}$, Laurel Young $^{d}$, Jesse Hoey ${ }^{c}$

${ }^{a}$ Dept. Occupational Science and Occupational Therapy, 160-500 University Ave., University of Toronto, Toronto, ON, M5G 1V7, Canada;

${ }^{\mathrm{b}}$ Toronto Rehabilitation Institute, 550 University Ave., Toronto, ON, M5G 2A2, Canada; ${ }^{\mathrm{S} S}$ chool of Computing, University of Dundee, Dundee, Scotland;

${ }^{d}$ Creative Arts Therapies, Sunnybrook Health Sciences Centre, Toronto, ON, Canada.

Corresponding Author: Dr. Alex Mihailidis, 160-500 University Ave., Toronto, ON, M5G 1V7, Canada. Ph: +1-416-946-8565; Fax: +1-416-946-8570;

email: alex.mihailidis@utoronto.ca 


\begin{abstract}
Art therapy is a growing field of interest in the care and maintenance of quality of life for persons with dementia. This paper describes research that had arts therapists participate in the identification of desirable features and functionalities of a computerbased tool for use in arts therapy with older adults who have dementia. The study targets the needs of art therapists and their clients, with the eventual aim of creating devices or software tools that will enhance art therapists' work with persons who have dementia. This paper describes the first two phases of the study: a multi-national survey, and the development of prototype devices based on the survey's results. First, results from the survey of creative arts therapists are presented along with an analysis of needs, practices, and ideas about technology. The paper then presents the three prototypes of potential art therapy technologies that were developed based on the findings from the survey. This research shows both a need for technological solutions in the domain of art therapy for persons with dementia, as well as a general acceptance and enthusiasm for technology as a clinical tool for practicing creative arts therapies.
\end{abstract}

Keywords: Art therapy, computer, artificial intelligence, dementia, elderly, assistive technology. 


\section{Introduction}

One goal of art therapy intervention with older adults with dementia is to improve or maintain quality of life through the promotion of autonomy and independence (Harlan, 1990) through participation in creative activities that have therapeutic goals (Karp, et al., 2006; Waller, 2002). Participation in artistic activities can provide persons who have dementia with ways of being meaningfully engaged or occupied (Killick \& Allan, 2001), which can in turn, increase their ability to engage with their environments, and/or provide an emotional outlet.

The cognitive difficulties that characterize dementia include trouble following instructions, remembering steps in a process, staying engaged, and making choices (Lubinski, 1991). Additionally, persons with dementia often forget what they are doing and need to be reminded of their task. However, there is increasing evidence that participation in creative activities can promote well-being (Kinney \& Cole, 1992), decrease the risk of dementia (Karp, et al., 2006; Verghese, et al., 2003), and slow cognitive decline (Wilson, et al., 2002). Specifically, research has shown that engagement with visual artwork can have quality of life benefits for older adults (Rusted, Sheppard, \& Waller, 2006).

Currently, there is a lack of funding and resources needed by art therapists to support the increasing number of persons with a progressive illness. This means that persons with dementia, for example, may spend long periods with no meaningful occupation, as caregivers are often busy with daily routines. These periods can reduce one's motivation and desire to independently engage in creative processes (Seligman, 
1975).

The authors propose that technology, specifically an artificially intelligent computer-based art device, has the potential to enhance art therapists' abilities to reach older adults with dementia by providing art activities that a person can engage with autonomously and independently. Importantly, this device is meant to be more than just games for leisure; it is specifically aimed to be used by art therapists as a tool for therapy. It is envisioned that this new tool will be able to provide different types of art therapy directives, will be useable by the older adult on his/her own or in collaboration with a therapist, will be able to automatically assess a user's level of engagement with the device, will prompt or cue as necessary to further engage the user in the activity, and will collect relevant data to evaluate the outcomes of the directive.

There has been a modest amount of research into the use of technology in art therapy. For example, there has been some research published on the use of technology in art therapy contexts, such as investigations on the use of video (Hartwich \& Brandecker, 1997) and digital photography (Wolf, 2007) as new tools in psychotherapy, which have yielded very positive results. With respect to computerbased art therapy (i.e., using technology as part of the art therapy process), only a limited number of technologies have been developed. Examples include a computer application that uses a touchpad as a tool to help children paint (Browne, Bederson, Druin, Sherman, \& Westerman, 2000), and Jabberstamp (Raffle, Vaucelle, \& Wang, 2006), which is a tool that allows children to add voices to their drawings. However, these applications are not practical for older adults with dementia because of required high levels of cognition and fine motor skills. Collie and Cubranic (1999) developed a 
computer based art therapy program for use in tele-health (Collie \& Cubranic, 1999), but their system required an art therapist to be physically present, and was not developed or tested with older adults with dementia. The majority of past computer-based applications have focussed on art therapy assessment, such as for judging the main colour in a drawing (Kim, 2008), detecting the placement of subject matte (Kim, Kang, \& Kim, 2008), and estimating the level of dementia based on elements in a structured Mandala drawing (Kim, Betts, Kim, \& Kang, 2009).

To date there has been no work on computer-based systems that can prompt and monitor a user's participation in creative arts similar to the technologies proposed in this paper. In addition, it should be noted that software tools that have been developed as "general" art technologies have not been included in this summary as they were not developed specifically as therapy tools. While some of these tools have been used in practice, there are no specific publications that support or disprove their usefulness.

This paper presents the first stages of work in the user-centered design and development of a computer-based art therapy device. First, the results of an online survey conducted with arts therapists in Canada and the United Kingdom are presented and analysed using ethnographic methods. Next, these results are coupled with the authors' knowledge of art therapy for people with dementia to develop a set of design constraints for devices that can be used by art therapists and their clients (Blunsden, et al., 2009). Finally, the paper presents the application of these design constraints to the development of three initial art therapy tool prototypes, called ePADs (engaging Platform for Art Development). These ePAD prototypes will be the basis for future focus groups with arts therapists and clinical trials with older adults with dementia. 


\section{Objectives}

The objectives of this work are to:

1. Define the type(s) of art activities that would be most appropriate to engage older adults with dementia (e.g., drawing, painting, collage making, etc.), both in terms of accessibility and initiation/continuation in the activities;

2. Determine the types and levels of necessary assistance/response a user would require;

3. Identify appropriate types of user interfaces, and

4. Identify the types of data the system should collect and make available to people of interest (e.g., a client's art therapist, other health care professional, family member, etc.).

\section{Methods and Approach}

A participatory design (PD) approach was used to determine the design criteria for this new technology and to assess the initial prototypes. PD attempts to actively involve all stakeholders (e.g. art therapists, older adults with dementia, caregivers) in the design process to help ensure that a product usable by and appropriate for its target population(s).

PD often employs ethnography, which is the study of human practices and interactions with and within the environment (Macauley, Benyon, \& Crerar, 2000). Ethnographers usually study their subjects through the qualitative analyses of one-onone discussions, focus groups, and surveys. Design ethnographers can study human interactions with objects that are situated in specific contexts, with a view to 
understanding the dynamic between human behaviour and the design of products and services (Macauley, et al., 2000).

To explore and define the problem, the authors (who include two creative arts therapists) developed a survey to gain a better understanding of the needs of art therapists and their clients. The survey employed a series of closed and open-ended questions, and used single-choice, multiple-choice, Likert scales, and text boxes to collect both quantitative and qualitative data. Table 1 summarizes the topics explored through the survey and key data collected for each. A copy of the full survey can be found online at: www.ot.utoronto.ca/iats//artsurvey.pdf.

\section{[INSERT TABLE 1 APPROXIMATELY HERE]}

The survey was hosted on the internet through Survey Monkey (www.surveymonkey.com). The web link for the survey along with an introductory letter was emailed to creative arts therapists in North America and the United Kingdom using mailing lists obtained from various professional societies and organizations. It should be noted that this mailing was not restricted to only those therapists who primarily work with visual art, but to all arts therapists (e.g., music therapy, etc.) This was done has it was felt that all arts therapists, regardless of their area of creative specialty, would have relevant information to offer, and because it is felt that eventually this type of technology may have application in other creative activities. The survey was kept open until a minimum of 100 respondents was received. Full ethics approval was received from the 
requisite research ethics boards for this study.

\section{Survey Results}

A total of 133 arts therapists participated in the survey. Survey respondents' demographics are presented in Table 2.

[INSERT TABLE 2 APPROXIMATELY HERE]

The respondents practiced in Canada (88), the UK (39), Ireland (1), The Netherlands (1), Switzerland (1), Taiwan (1), USA (1), and unknown (1). The respondents focused on a broad spectrum of specialty areas, with mental illness (32.1\%), loss and grief (26.0\%), and Alzheimer's-type dementia (24.4\%) reported as the three highest areas of expertise.

The types of arts therapy practiced by the respondents were also broad, with visual arts (78.7\%), music (31.5\%) and writing (22.8\%) reported as the most used activities. Of the 57 respondents who worked with older adults, 46 (81\%) specifically worked with people who have dementia. Of these respondents, 39 of the 46 practiced in Canada.

The majority (92\%) of UK therapists estimated that they usually worked with their clients once a week, whereas Canadian therapists estimated that they saw their clients two or more times a week (14\%), once a week (68\%), or more than once a month (14\%). Most respondents who worked with older adults with dementia saw their clients

at least once a week, with $25 \%$ reporting that they saw their clients two or more times a 
week and $61 \%$ reporting once a week. Figure 1 depicts the location(s) where respondents practiced creative arts therapies with their clients.

\section{[INSERT FIGURE 1 APPROXIMATELY HERE]}

Respondents who worked with older adults (both with and without dementia) felt their clients most enjoyed painting (80\%), drawing (63\%), and sculpture (43\%). Dance (30\%), finger painting (27\%), and writing (25\%) were modestly ranked while music composition (18\%) and theatre performances $(8 \%)$ were the least often used. Other tasks, such as singing, collage, and constructing small objects (e.g., building a bird house) were listed five or more times in the "other" category. When considering these results, it should be kept in mind that respondents likely only commented on their area(s) of practice (e.g., a music therapist probably would not share an opinion regarding how much his/her clients enjoy painting).

When deciding which creative activity to do, most respondents felt the selection process was guided by the client, with $84 \%$ of the UK and $67 \%$ of the Canadian respondents stating that their clients usually select the activity they wish to do. Canadian therapists were more likely to give guidance to clients than UK therapists, as shown in Figure 2. Figure 2 also shows that respondents who work specifically with older adults with dementia tend to recommend higher levels of activity guidance; however, this trend could be at least partially impacted by the high percentage $(85 \%)$ of therapists in this category who practiced in Canada. 


\section{[INSERT FIGURE 2 APPROXIMATELY HERE]}

This discrepancy in the amount of guidance given to clients may be reflected in the respondents' answers to questions investigating potential ways 'tools and colours' should be selected when using a computerised arts therapy device. Specifically, 36.6\% of Canadian, $60 \%$ of UK, and $33.3 \%$ of older adult with dementia therapists (regardless of location) felt the client should select all shapes/colours used, and $63.4 \%$ Canadian, $37.1 \%$ UK, and $66.7 \%$ of older adult with dementia therapists felt the device should make the selection for the client if the client was unable to do so.

Regardless of their location or client-base, respondents felt the most strongly that the device should allow the client to select colours, be able to print and save copies of their art, and to use classic 'tools' (such as a paintbrush). Results concluded that the respondents were least in favour of the device auto-correcting shaky lines, playing background music, and performing auto-filling of a shape the client is trying to colour in. In these categories, respondents who worked with older adults with dementia followed the same trend of preferences as the respondent group as a whole.

Respondents from both Canada and the UK had very similar rankings in their approach to engaging clients, with visual, verbal, and gestural being the most commonly used techniques. Most therapists (89\%) who worked with older adults with dementia stated they used facial expressions to tell if a person was engaged. All therapists felt the device should be designed to be used individually as well as in group settings.

In terms of device feedback for the therapist, $87 \%$ of respondents would like to know which activities the client did with the device, followed by the number of times the 
client used the device ( $71 \%$ of respondents), if anyone else / who else was used the device $(70 \%)$, and the time of day the device was used (54\%). The majority of respondents (85\%) felt they would like to interact with the device through a touchscreen and $29 \%$ wanted the option to use a keyboard/mouse as well.

Therapists commented that they considered a successful outcome to be when their clients have a "smile on their face", demonstrate a "positive change", become more relaxed, or are generally engaged in the creative arts process. Lack of confidence, physical difficulties with materials and tools, and confusion and memory problems were cited as the main difficulties or barriers older adults face when attempting to engage in creative arts activities. In addition to sharing tasks with arts therapists, $83 \%$ of respondents who work with older adults with dementia felt that the device should be capable of having shared creative tasks that could be done with family members, compared to $66 \%$ of therapists who did not work with this population.

\section{Ethnographic Analysis}

The survey results were analyzed using ethnographic techniques and two major categories were found: structural implications and design implications. Structural implications relate to the underlying abilities of the device in its functioning, whereas design implications relate to the perceived interface of the device. Four major structural (S1-S4) and seven major design (D1-D7) implications were identified.

\section{S1: Customisability}

Customisation by arts therapists would include selection of activities and levels of 
difficulty. Beyond this, the device itself could even be configurable by the arts therapist, such as allowing the therapist to drag-and-drop activities and materials onto the project space according to the skills, needs, and preferences of the client as determined in previous evaluative sessions.

\section{S2: Adaptivity}

The device should adapt to individual users. This is especially important in the case of art therapy for people with dementia, since the disease involves a progression through various stages of ability. In current practice, early evaluative sessions provide insight to arts therapists about the appropriate level of choice for their clients. These sessions also provide insight into the preferences of clients (e.g., for materials). Bearing this in mind, the art therapy tool should be able to learn each user's preferences and individualize materials, activities, and activity difficulty to suit the needs of each client, both initially and over time.

\section{S3. Passivity}

Individuals with dementia may require a more directive (i.e., hands-on, therapistled, guided) approach at times, though it is generally considered preferable to leave decision making in the hands of the clients. Such practice provides the arts therapist with greater insight into the client's state of mind than if the therapist tells the client what to do. However, to mitigate problems of user memory, a device should react to signs of confusion, disengagement, or inactivity, by reminding clients of their task, demonstrating the task, and automatically selecting options such as colors and shapes. 


\section{S4: Assessment}

Computerised devices should provide quantitative measures to be used for assessment purposes. Arts therapists currently use refined qualitative measures over time to determine clients' individual abilities, needs, and goals. It would be a benefit to art therapists to have a tool that enabled them to quickly assess and evaluate the abilities and affective responses of new clients, in particular so that an individual's needs do not get lost in a group setting.

\section{D1: Choice}

A key element in empowering clients through art making is providing them with opportunities to choose. Many people with dementia can feel disempowered in their day-to-day lives, having very few chances to make decisions and possibly feeling like no one is listening to them. The art therapy tool, therefore, should aim to offer choice of activity, materials, and colors.

\section{D2: Simplicity}

In all arts therapy contexts, but arguably especially for clients with dementia, it is important to avoid overwhelming the client. This implies a design that limits options, thereby decreasing decision-making stress. However, a blank canvas can be intimidating, so an interface should always present at least a small set of choices. It is recommended to start users with the most minimal possible starting point appropriate for their current level of ability. 


\section{D3: Touch}

Persons with dementia often have accompanying physical difficulties that come with ageing. Buttons and text need to be large for those with poor vision, and audio feedback and instructions need to be loud for those who are hard of hearing. Impairment of manual dexterity is a frequent obstacle for art therapists, as older clients often had trouble holding objects such as paintbrushes. Arts therapists overwhelmingly agreed that a touch screen is the most viable option.

\section{D4: Saving and reviewing work}

Beyond the affective considerations for allowing clients to engage with their creations, the works of art are used by therapists for a variety of reasons, including prompting of memory recall. Although persons with dementia may not remember having made their artwork, it is important that the art work be saved, and for a user to see and share the products of their creative efforts.

\section{D5: Tangible interfaces}

The use of a touch screen interface raised additional design concerns, namely: (1) how to ensure the user understood how to use the device; and (2) how to preserve the sensory components of the art making process. The proposed solution to the first concern is to design an interface to match the real world action of the art making activity. For example, the device could respond to the natural movement of pouring paint. To address the second concern, the device should somehow incorporate the 
tactile elements into the activity, and to link the art materials to the sounds they would naturally make (e.g., linking spray paint to a spraying sound).

\section{D6: Art therapist involvement}

The goal of an art therapy device should not be to replace the art therapist, as this relationship is a crucial component of the effectiveness of the therapy. In fact, the device could benefit from the therapist's case-by-case expertise by allowing him or her to participate in shaping the activities that are best suited to individual clients. This means designing the device in such a way that the art therapist has control over the activities the client can choose to do, including level of difficulty. The proposed device will address this by allowing art therapists to program the device to some degree, in order to implement the appropriate arts tasks for their clients.

\section{D7: Feedback}

Knowing the activities the client completed with the device was ranked as the most important feedback for the therapists, followed by the number of times they used the device, who else was using the device, and the time of day the device was used. Survey respondents articulated their desires to know the activities, lengths of time, which activities were done on the device, how long the client spent doing art, the time that the device was used, who else used the device, whether the client worked alone or with assistance, the number of prompts required, and measures of client abilities.

Therapists would like to be able to see trends in these features over time in order to assess progress or a decline in ability. Feedback to art therapists should ideally be 
presented in a visual manner, and in a format that complements the qualitative assessments usually practiced by art therapists. A proposed solution is to present feedback in the form of several sliding scales, which would offer a visual of the client's position on a continuum. Possible continuums include the degree of difficulty of activity, the user's level of engagement, and the user's degree of frustration.

\section{Prototype Development}

Based on the findings from the survey and the ethnographic analysis of the data, three initial prototype ePAD devices were developed. These prototypes only incorporate design constraints S2-S3 and D1-D3. However, the structure of the device allows for easy implementation of the remaining criteria in future prototypes.

\section{Device Overview}

A diagram of an ePAD is given in Figure 3. The user interface (a painting program in this case) is displayed on a touch screen monitor. A webcam provides video showing the user from some perspective (e.g., placed above the monitor, directly in front of the person), and a computer vision system recognises whether someone is looking at the screen. The face presence, along with the interaction of the user with the screen (e.g., where they have been touching), are passed to an artificial intelligence (Al) system.

The Al system uses a model known as a partially observable Markov decision process (POMDP) to estimate what it believes about the person's current state (i.e., what they are currently doing). The POMDP model uses prior information about what inputs it is most likely to see as a result of different actions by the user, and then deduces what is 
likely going on based on the observations of these inputs. For example, the POMDP knows that a person who is engaged with the device will often spend more time with his/her finger on the screen. Therefore, if a user keeps his/her finger on the screen (an observation), the POMDP will interpret this as the user being more engaged. The device is also able to estimate how responsive the person is to certain prompts, what level of behavior he/she is exhibiting (e.g., are they being very active or are they inactive), and what elements of the application he/she has used or completed (e.g., if the screen is full of colour). Based on these observations and estimates, the device selects an action to take that is appropriate for what the user is doing and what his/her preferences are. This action is delivered to the interface (e.g., touch-screen), possibly accompanied by an audio prompt if there are speakers.

The following sections presents three example ePADs. The first section goes into some detail and gives an example of an interaction with a user, while the second and third provide more brief overviews.

\section{[INSERT FIGURE 3 APPROXIMATELY HERE]}

\section{ePAD I: Finger painting on vertical touch screen}

ePAD I involves a painting application in which blobs of color are placed on a canvas (i.e., the touch-screen) with a simple background (i.e., a line drawing). The user can mix the colors with his/her finger, with realistic blending effects. A background image, such as the outline of a sailboat or a kite, and a few blobs of colour are always present on the screen. The device also monitors a person's face to estimate his/her 
engagement. The application can change its state in two ways, either by adding new colour blobs on the screen or by changing the background image. ePAD I uses a NEC Multisync LCD 2010X touch screen running on a standard desktop, with a Logitec Quick Cam Pro 9000 mounted above the screen. Figure 4 shows examples of the interface.

\section{[INSERT FIGURE 4 APPROXIMATELY HERE]}

Figure 5 shows an example of a person who is responsive to system actions and who is engaged in the task. The system initially plays an audio prompt giving instructions on what to do. The system then observes that a person's face is present but that they haven't used the application in the last 5 seconds since the prompt was issued. At time $t=0$, their behaviour is determined to be inactive $(B E H A V I O U R=M)$. At $t=5$ the system adds a blob of colour, and observes that the user "plays" with it by touching the added blob of colour at $t=10$. This causes the device to estimate that the user is more interactive, engaged, and responsive to colours, as represented by increases in BEHAVIOUR $=I$, ENGAGED $=Y$, and COLOUR RESPOND $=Y$. The person then continues to interact with the system, increasing BEHAVIOUR $=A$ and $E N G A G E D=Y$. When the person is engaged the system takes no actions, but instead allows the user to explore the activity on his/her own.

[INSERT FIGURE 5 APPROXIMATELY HERE]

\section{ePAD II: Collage on Multi-Touch Surface}


ePAD // involves a collage of multi-coloured objects over a background picture.

Figure 6 shows an example application running on ePAD II with leaves for objects and a tree as the background picture. The user can drag the objects around and "glue" them down using simple gestures (e.g., a double tap of a finger). There are two buttons that allow a user to drop random objects on the surface ("drop"), and to get rid of un-stuck objects ("brush"). The user behaviours are drag, glue, drop, or brush. The actions available to the device are to drop, brush, or give a motivational prompt.

\section{[INSERT FIGURE 6 APPROXIMATELY HERE]}

The interface is a FTIR (frustrated total internal reflection) multi-touch surface embedded into a custom-built coffee table with a computer inside the table to run all the software. ePAD II is able to detect multiple fingers and objects when they come into contact with the interface, allowing multiple people (e.g., a therapist and client together) to use ePAD II simultaneously.

\section{ePAD III: Flipbook on Blade Tablet}

ePAD III is a flipbook animation and is shown in Figure 7. A user can create and review simple animations using freehand line drawing. Buttons are used to add a new frame, change from a pen to an eraser, and to play/stop the animation. Possible system actions are to suggest drawings, to highlight buttons, or to give prompts, although the dynamic nature of the artwork makes the precise modeling of the effects of system actions more involved. 


\section{[INSERT FIGURE 7 APPROXIMATELY HERE]}

The display for this ePAD is a PaceBlade touch tablet. This small device is very portable, and has a sensitive single-touch screen that can be used with a finger or a pen. The advantages of this tablet are its portability and sensitivity, and the main disadvantage is size.

\section{Conclusions and Future Work}

This paper presents the first stages in the development of a new technology for use in art therapy with older adults with dementia. The analysis of the online survey supports the notion that technological solutions are considered to be an acceptable and viable option for the promotion of engagement in therapeutic creative activities by older adults with dementia.

From the survey it was identified that this new technology should focus on painting and drawing activities, as these were the creative activities that survey respondents felt older adults with dementia would enjoy the most. The respondents also felt that while some guidance should be provided to the user, the system should allow the user to selfselect the activities being performed and should involve the therapist as much as is needed. Therapist interactions should also involve the option of "co-creation" of art between the user and therapist using the device. Furthermore, the feedback to the user from the device should use different modalities, including visual and verbal prompts. Finally, the survey revealed that throughout this process the system should be able to 
assess the necessary amount of interaction and guidance through the monitoring of the user's facial expressions and how engaged the person is in the completion of the activity itself.

Based on these findings, the authors have developed three different prototypes of potential art therapy devices, which attempt to incorporate some of the key design constraints discussed throughout this paper. Future work will involve further refinement of these prototypes through the completion of a focus group involving several creative arts therapists. The goal of this focus group is to study the themes that were identified by the ethnographic analysis of the online survey in depth, as well as presenting an opportunity for the therapists to interact directly with the design team members and the three prototypes. Data from the focus group will be used to modify and consolidate the three ePAD prototypes into a single second-generation prototype, which will be tested through clinical trials with older adults with dementia.

The development of technologies that can help facilitate participation in art therapy and other forms of therapeutic creative expression among older adults with dementia could result in great benefits to not only clients, but to arts therapists as well. These new tools could have the potential to allow therapists to reach more clients and to facilitate therapeutic interventions more efficiently. In addition, this type of technology may provide a user with more frequent access to therapeutic entertainment in their own free time, giving them a greater feeling of independence and satisfaction. Furthermore, future versions of this software could investigate the feasibility of this technology being used for different populations, such as children suffering with autism. 


\section{Acknowledgements}

This work was supported by the American Alzheimer's Association under the Everyday Technologies for Alzheimer's Care program. We thank Patrick Olivier, Tom Bartindale, and Dan Jackson for their work on the interfaces and multi-touch table, and Jane Burns for her help in the initial phases of this project. 


\section{References}

Blunsden, S., Richards, B., Bartindale, T., Jackson, D., Olivier, P., Boger, J. N., et al. (2009). Design and prototype of a device to engage cognitively disabled older adults in visual artwork. Paper presented at the ACM 2nd International Conference on Pervasive Technologies Related to Assistive Environments (PETRA), Greece.

Browne, H., Bederson, B., Druin, A., Sherman, L., \& Westerman, W. (2000). Design a collaborative finger painting application fo children: University of Maryland $\mathrm{HCl}$ Lab Technical Report.

Collie, K., \& Cubranic, D. (1999). An art therapy solution to a telehealth problem. Art Therapy, 16(4), 186-193.

Harlan, J. (1990). Beyond the patient to the person aspects of autonomous functioning in individuals with mild to moderate dementia. The American Journal of Art Therapy, 28(4), 99-106.

Hartwich, P., \& Brandecker, R. (1997). Computer-based art therapy with inpatients: Acute and chronic schizophrencis and boderline cases. The Arts in Psychotherapy, 24(4), 367-373.

Karp, A., Paillard-Borg, S., Wang, H., Silverstein, M., Winblad, B., \& Fratiglioni, L. (2006). Mental, physical and social components in leisure activities equally contribute to decrease dementia risk. Dementia and Geriatrics Cognitive Disorders, 21(2), 65-73. 
Killick, J., \& Allan, K. (2001). Communication and the care of people with dementia. Buckingham: Open University Press.

Kim, S. (2008). Computer judgment of main color in a drawing for art psychotherapy assessment. The Arts in Psychotherapy, 35, 140-150.

Kim, S., Betts, D. J., Kim, H., \& Kang, H. (2009). Statistical models to estimate level of psychological disorder based on a computer rating system: An application to demetnia using structured mandala drawings. The Arts in Psychotherapy, 36, 214-221.

Kim, S., Kang, H., \& Kim, K. (2008). Computer determination of placement in a drawing for art therapy assessment. The Arts in Psychotherapy, 35, 49-59.

Kinney, W., \& Cole, C. (1992). Predicting life satisfaction among adults with physical disabilities. Archives of Physical Medicine and Rehabilitation, 73, 863-869.

Lubinski, R. (1991). Dementia and Communication. Philadelphia: B.C. Decker, Inc. Macauley, C., Benyon, D., \& Crerar, C. (2000). Ethnography, theory and design: From intuition to insight. Journal of Human-Computer Studies, 53, 35-60.

Raffle, H., Vaucelle, C., \& Wang, R. (2006). Jabberstamp. Retrieved December 13, 2006, 2006, from http://www.rafelandia.com/jabberstamp/index.html

Rusted, J., Sheppard, L., \& Waller, D. (2006). A multi-centre randomized control group trial on the use of art therapy for older people with dementia. Group Analysis, 39(4), 517-536.

Seligman, M. E. P. (1975). Helplessness: On Depression, Development, and Death. San Francisco: W.H. Freeman. 
Verghese, Lipton, R. B., Katz, M. J., Hall, C. B., Derby, C. A., Kuslansky, G., et al. (2003). Leisure activities and the risk of dementia in the elderly. New England Journal of Medicine, 348(25), 2508-2516.

Waller, D. (2002). The difficulty of being. In D. Waller (Ed.), Arts Therapies and Progressive IIIness. London: Routledge.

Wilson, R. S., Leon, C. F. M. d., Barnes, L. L., Schneider, J. A., Bienias, J. L., Evans, D. A., et al. (2002). Participation in cognitively stimulating activities and risk of incident of Alzheimer disease. Journal of the American Medical Association, 287(6), $742-748$.

Wolf, R. I. (2007). Advances in phototherapy training. The Arts in Psychotherapy, 34, 124-133. 


\section{Figure Captions}

Figure 1: Location(s) where survey respondents engaged in arts therapies with their clients.

Figure 2: Amount of guidance given to clients during arts therapy reported by survey respondents.

Figure 3: Functional overview of the ePAD device.

Figure 4: The application and the actions which can be performed upon it. The only action a user can do is to mix (smudge) the colours. The device can add colour blobs (add paint) and/or change the background line drawing (not shown).

Figure 5: Example sequence of an engaged user. The task time runs at the top of the Figure, from left to right, in 5 second increments. Snapshots of the user interface are presented with corresponding observations by the device below. From these observations, the device estimates different features, namely BEHAVIOUR [interactive $(\mathrm{I})$, active $(\mathrm{A})$, intermittent $(\mathrm{M})$, and inactive $(\mathrm{N})$ ], ENGAGED [no $(\mathrm{N})$, confused $(\mathrm{C})$, and yes $(\mathrm{Y})$ ], and COLOUR RESPOND [yes $(\mathrm{Y})$ and no $(\mathrm{N})$ ]. The value (height) of each a bar denotes how strongly the device believes that the corresponding condition represents the state of the user, with a higher value representing a greater belief. The actions taken by the system are selected according to the values of these features; actions taken by the device for this example are presented along the bottom of the 
Figure.

Figure 6: An ePAD II collage on a custom-built multi-touch table.

Figure 7: Drawing using ePAD III on a Blade Tablet PC. 
Table 1. Topics explored and primary data collected through the online survey

\begin{tabular}{|l|l|}
\hline \multicolumn{1}{|c|}{ Questionnaire Topic } & \multicolumn{1}{|c|}{ Primary Data Collected } \\
\hline Demographics & $\begin{array}{l}\text { Years of experience, credentials, client } \\
\text { populations, primary specialty areas }\end{array}$ \\
\hline Population of focus & $\begin{array}{l}\text { Specific population that the respondent } \\
\text { will use in response to survey } \\
\text { questions, years of experience with this } \\
\text { specific population }\end{array}$ \\
\hline Facilitating creative expression & $\begin{array}{l}\text { Location of therapy, commonly used } \\
\text { forums, frequency of sessions }\end{array}$ \\
\hline Engagement of clients & $\begin{array}{l}\text { Techniques used to engage clients, } \\
\text { cue and feedback provided }\end{array}$ \\
\hline Features of a computer-based system & $\begin{array}{l}\text { Measures used to determine outcomes } \\
\text { applications it should run, amount of } \\
\text { interaction with the technology, } \\
\text { interface features }\end{array}$ \\
\hline Feedback from the device & $\begin{array}{l}\text { Type of feedback required, frequency } \\
\text { of feedback }\end{array}$ \\
\hline $\begin{array}{l}\text { Creative expression with older adults } \\
\text { with dementia }\end{array}$ & $\begin{array}{l}\text { Number of years worked with this } \\
\text { specific population, difficulties and } \\
\text { barriers to working with this population }\end{array}$ \\
\hline
\end{tabular}


Table 2: Demographics of respondents to the computerized art therapy tool survey

\begin{tabular}{|c|c|c|c|c|c|}
\hline \multicolumn{2}{|c|}{ Experience } & \multicolumn{2}{|l|}{ Focus Population(s) } & \multicolumn{2}{|l|}{ Employment } \\
\hline Years & $n(\%)$ & Population(s) & $n(\%)$ & Employer(s) & $n(\%)$ \\
\hline $0-2$ & $16(12.0)$ & Children & 75 (56.4) & Self-employed & $70(52.6)$ \\
\hline $2-4$ & $22(16.5)$ & Youth & $62(46.6)$ & Acute care facility & $14(10.5)$ \\
\hline $4-6$ & $15(11.3)$ & Adults & $94 \quad(70.7)$ & Long-term care facility & $33(24.8)$ \\
\hline $6-8$ & $10(7.5)$ & Older adults & $57(42.9)$ & University/College & $6(4.5)$ \\
\hline $8-10$ & $10(7.5)$ & Families / Couples & 32 (24.1) & Government program & $12(9.0)$ \\
\hline $10+$ & 59 (44.3) & School / Business groups & $23(17.3)$ & Other & $68(51.1)$ \\
\hline Unknown & $1(0.75)$ & Women & $34(25.6)$ & & \\
\hline & & Aboriginals & $12(9.0)$ & & \\
\hline & & Other & $21(15.8)$ & & \\
\hline
\end{tabular}




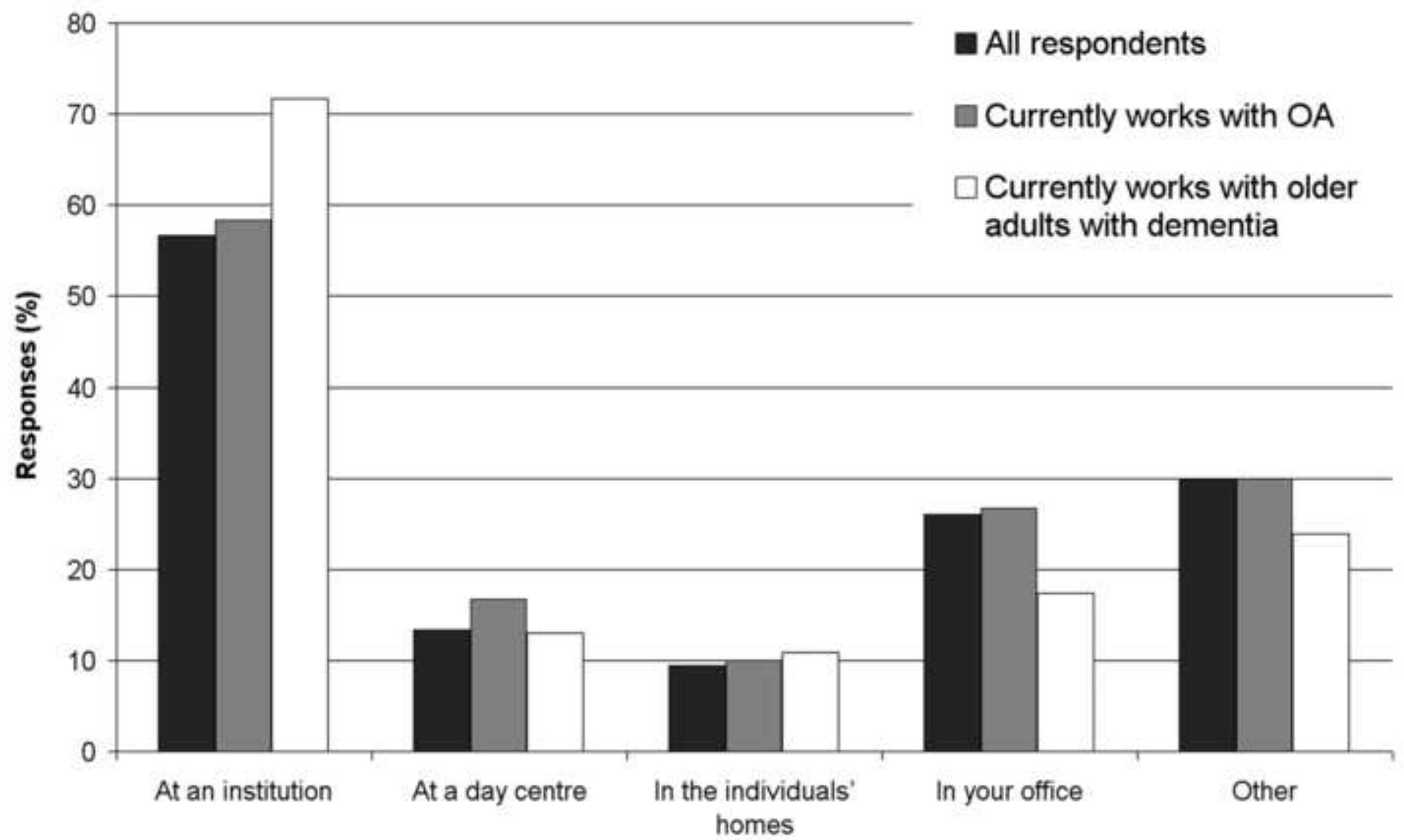

Location(s) of Arts Therapy Sessions 


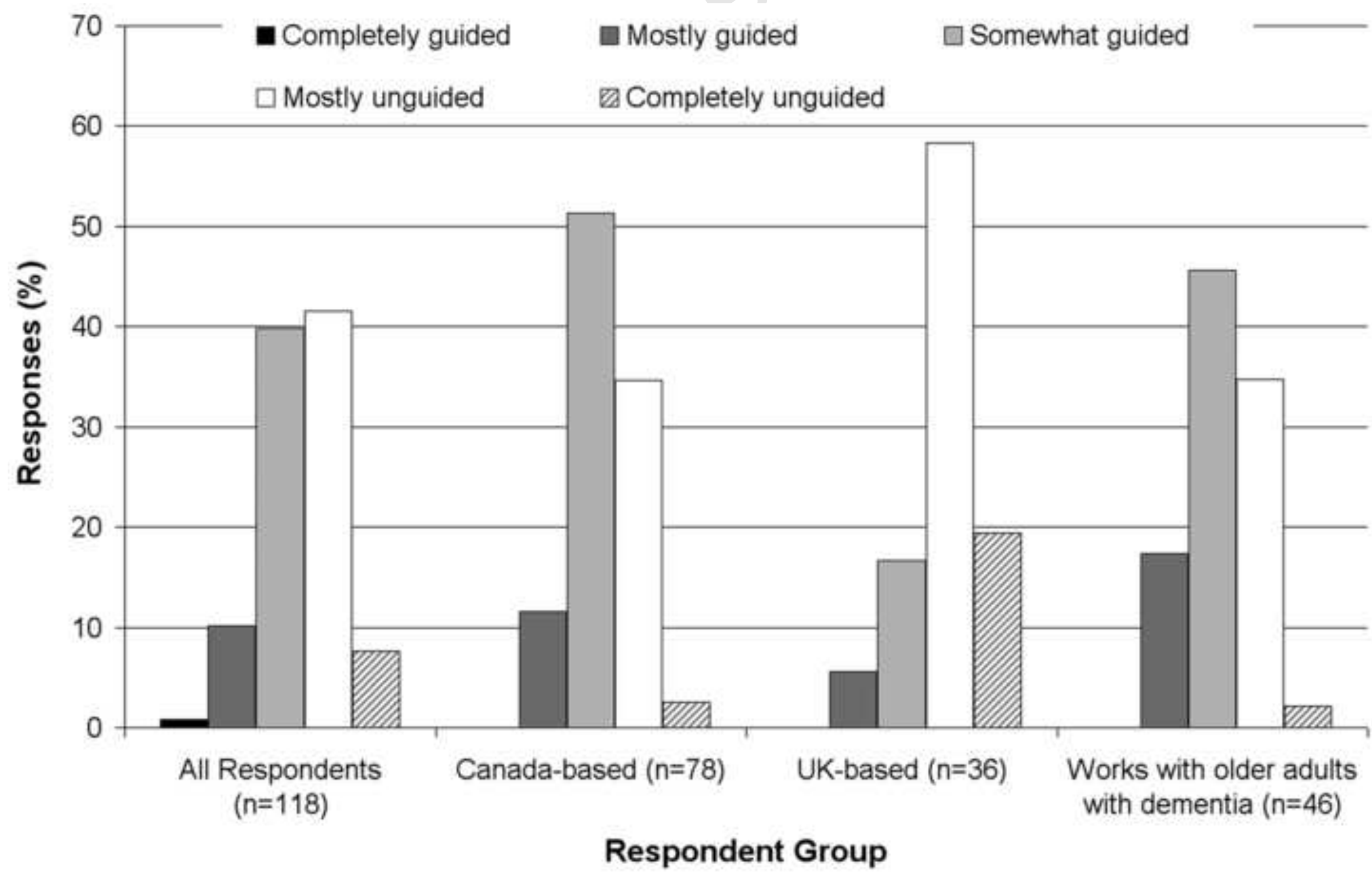




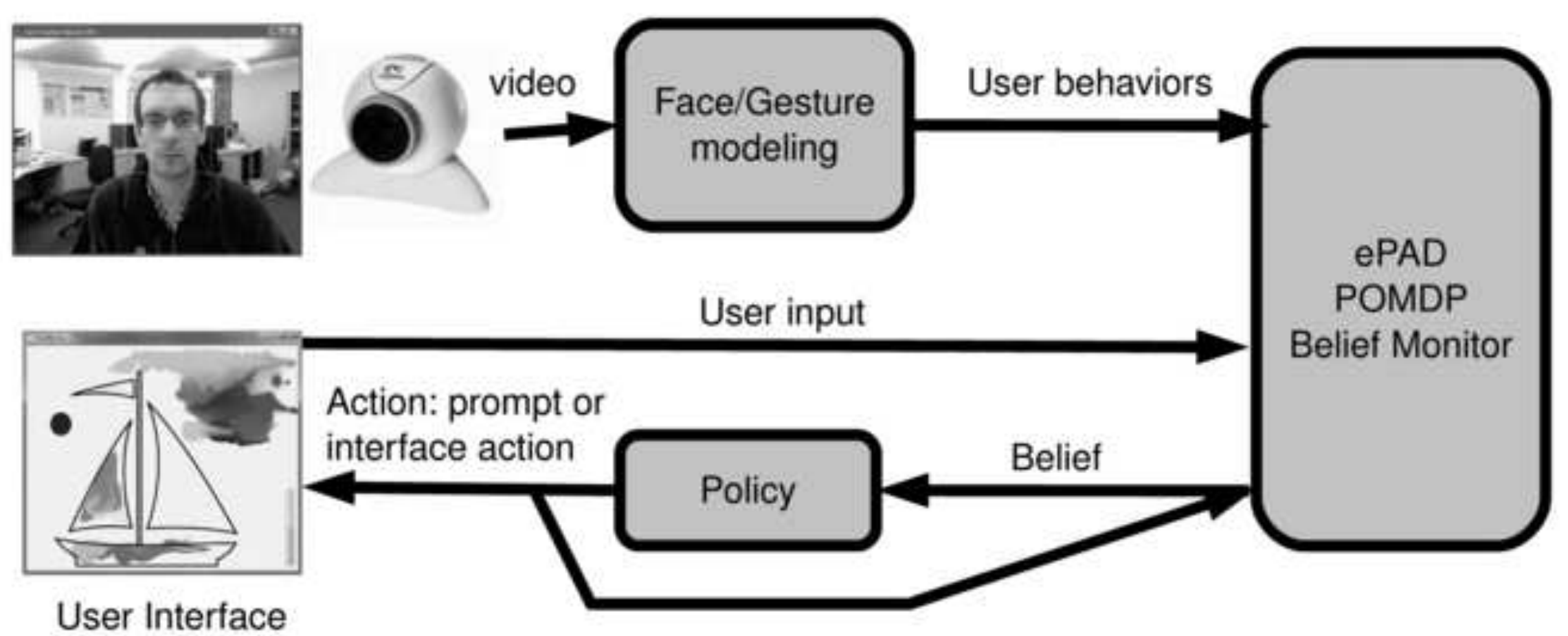



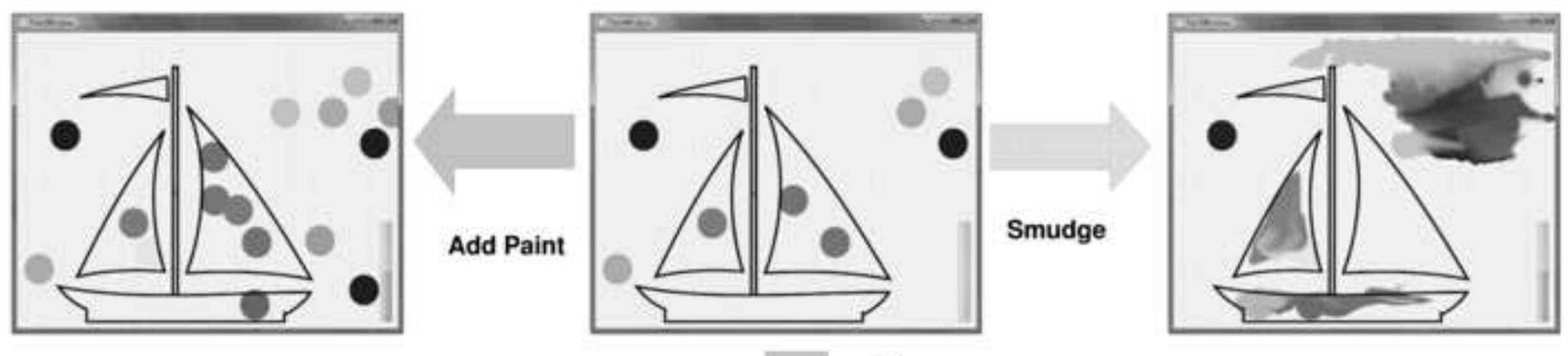

\section{Change}

Background

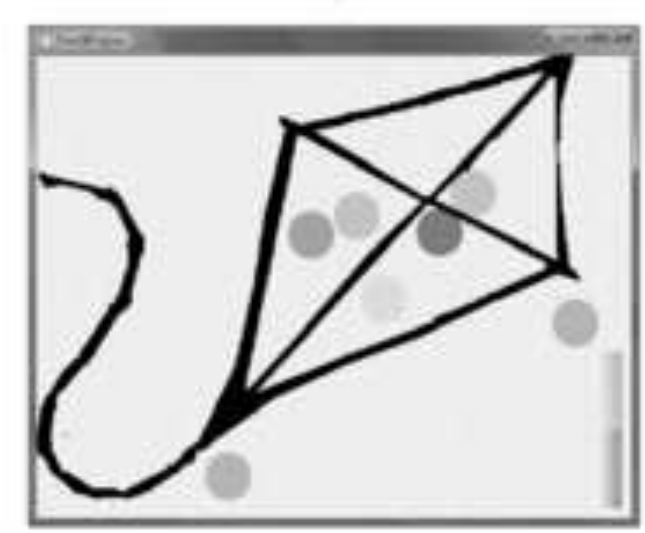



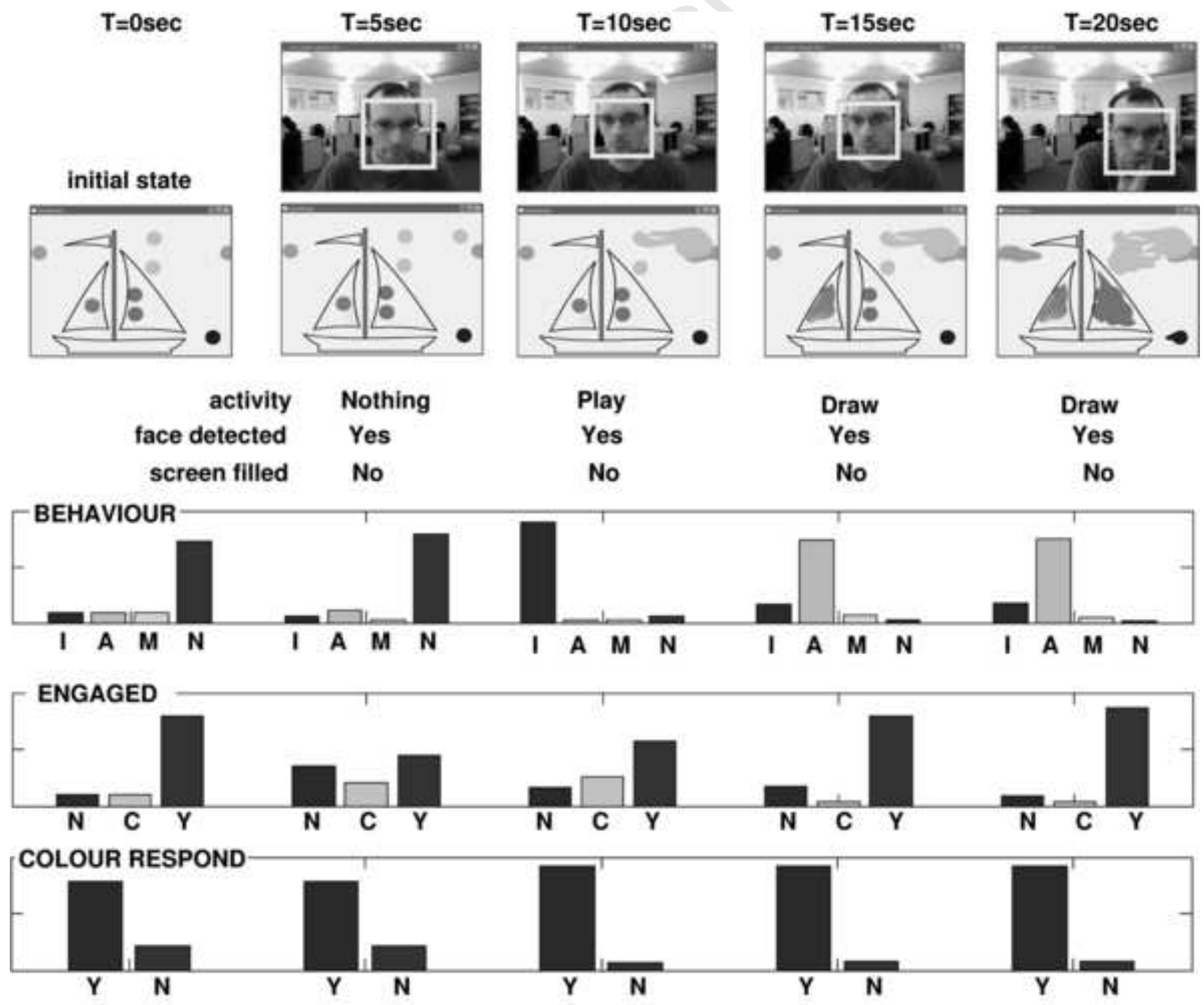

ACTION:

prompt

add colour

nothing

nothing

rage 34 or 36

nothing 

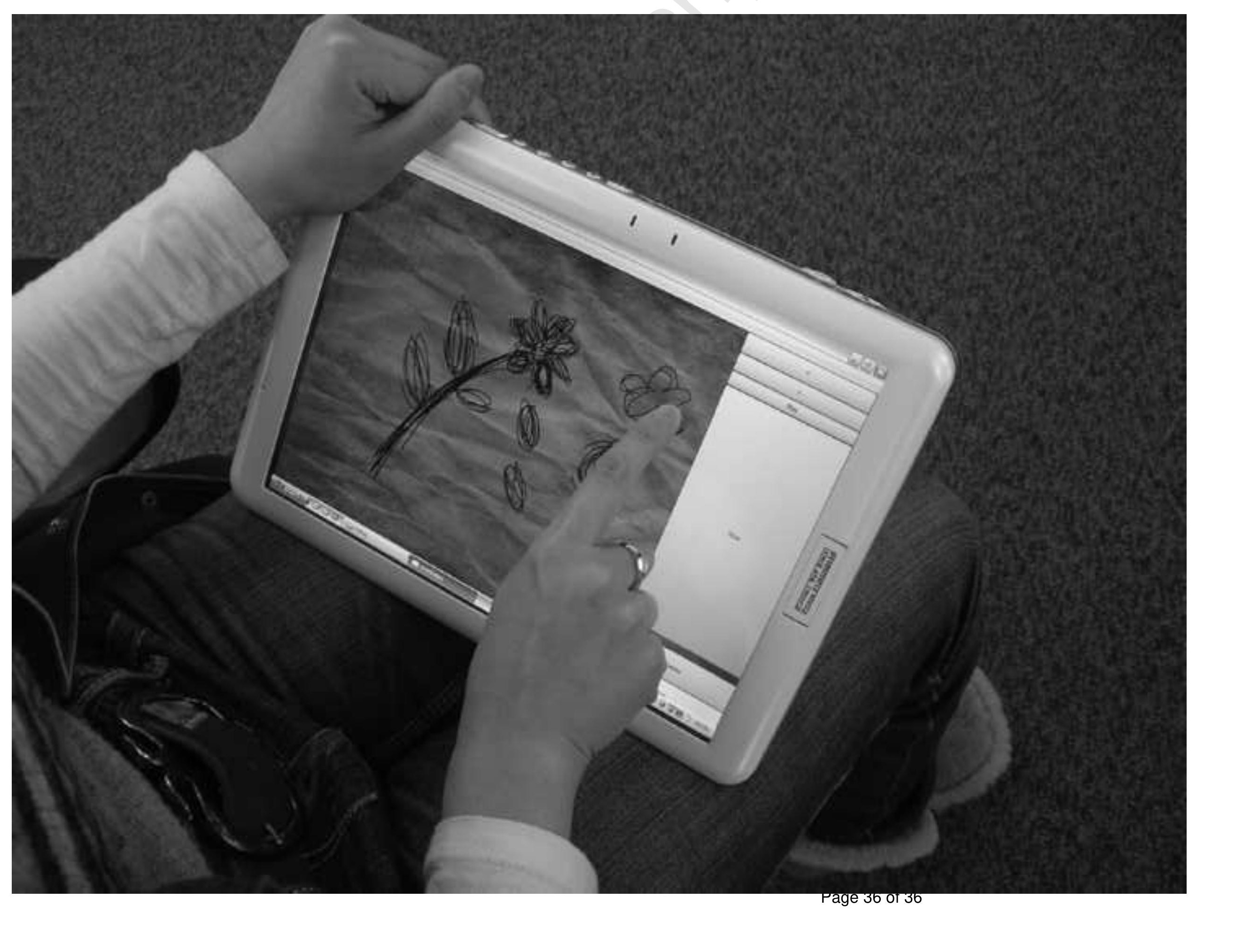

7

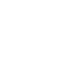

